Iranian Journal of Pathology | ISSN: 2345-3656

\title{
Risk-based Stratification of Salivary Gland Lesions on Cytology: An Institutional Experience
}

\author{
Pooja Jaiswal', Mousumi Sharma1", Faraz Ahmad², Nausheen Sanaullah Khan', Siddhartha Shanker Sinha ${ }^{1}$, \\ Megha Agarwal ${ }^{1}$ \\ 1. Dept. of Pathology, Integral Institute of Medical Sciences and Research, Lucknow, India \\ 2. Dept. of Surgery, King George Medical University, Lucknow, India
}

\begin{tabular}{c}
\hline KEYWORDS \\
\hline FNAC; \\
Salivary Gland Lesions; \\
Risk-based Stratification; \\
Milan System \\
\hline
\end{tabular}

\section{Article Info}

Received 10 Oct 2017; Accepted 03 July 2017;

Published Online 17 July 2018;

\section{ABSTRACT}

Background \& objective: Fine needle aspiration cytology (FNAC) of salivary gland lesions is an accepted and useful diagnostic tool to differentiate between benign and malignant lesions. Majority of the neoplasms are benign, and specific diagnosis on cytology can be made in most of the cases. However, the utility is limited by the overlapping and heterogeneous morphological features of benign and malignant neoplasms. The current study aimed at investigating the cytomorphological features of salivary gland lesions with histopathological correlation and performing risk based stratification of these lesions using the recommended Milan system for reporting of salivary gland cytopathology (MSRSGC).

Methods: The current study was conducted on 192 retrospective and prospective cases of salivary gland lesions over a period of three years from October 2014 to September 2017. Cytohistopathological correlation was observed in 62 cases. Subsequently,cytomorphological features were further revaluated, classified according to MSRSGC into six groups, and correlated with clinico-histopathological features.

Results: Diagnostic sensitivity and specificity of FNAC for salivary gland lesions was $63.16 \%$ and $97.62 \%$, respectively. The positive predictive value was $92.31 \%$ and negative predictive value was $85.42 \%$. The diagnostic accuracy to differentiate between benign and malignant lesions was $86.88 \%$. The number of cases in each diagnostic category and the risk of malignancy (ROM) were as follows: nondiagnostic - three cases (ROM - 33.33\%), nonneoplastic - 14 cases (ROM - 7.14\%), atypical - one case (ROM - 100\%), benign - 28 cases (ROM - 7.14\%), NUMP - one case $(\mathrm{ROM}-100 \%)$, suspicious - one case (ROM -100\%), and malignant - 13cases (ROM - 92.30\%).

Conclusion: Risk based stratification scheme as recommended by MSRSGC can provide a standard method to analyse the results and help to plan the management of salivary gland lesions.

Copyright (C) 2018, IRANIAN JOURNAL OF PATHOLOGY. This is an open-access article distributed under the terms of the Creative Commons Attribution-noncommercial 4.0 International License which permits copy and redistribute the material just in noncommercial usages, provided the original work is properly cited.

\section{Introduction}

Salivary glands are compound exocrine glands classified into parotid, submandibular, sublingual and minor salivary glands found throughout the oral cavity and oropharynx (1). Cytomorphological spectrum of salivary gland lesions ranges from non-neoplastic lesions to neoplastic benign and malignant lesions. Salivary gland neoplasms are relatively uncommon and represent $6 \%$ of all head and neck neoplasms (1).
FNAC is an accepted and useful diagnostic tool to evaluate salivary gland lesions (2). It is preferred over histopathological methods such as incisional or needle biopsy as they have a risk of increased infection and contamination of operative field with tumor cells (3). FNAC helps to decide whether the lesion is of salivary gland origin or from adjacent tissue, classifying them into non-neoplastic and neoplastic lesions and further classifying neoplastic lesions into benign 
and malignant. The diagnostic sensitivity ranges from $81 \%$ to $100 \%$, specificity from $94 \%$ to $100 \%$ and the accuracy from $61 \%$ to $80 \%$ (4), which is mainly due to relative rarity of these lesions, low cellularity, heterogeneity, and overlapping cytomorphological features. Therefore, considering the limitations such as low sensitivity and high performance heterogeneity, it is important to report salivary gland FNAC on the basis of a risk based diagnostic classification scheme for effective clinical management of patients $(5,6)$. The American Society of Cytopathology and the International Academy of Cytology initiated a project to propose a classification scheme (the Milan system) to report salivary gland FNAC. This scheme included six categories: non-diagnostic, non-neoplastic, atypia of undetermined significance, neoplastic- a) benign or b) uncertain malignant potential, suspicious to malignancy, and malignant (7).

The current study presented cytomorphological features of 192 salivary gland lesions, their risk based stratification based on Milan system along with their cyto-histopathological correlation and determination of efficacy of FNAC.

\section{Material and Methods}

The current study was conducted on 192 cases of salivary gland lesions in the Department of Pathology, IIMS\&R, Lucknow (UP), retrospectively and prospectively for a period of three years from October 2014 to September 2017. The patients' age ranged from 6 to 85 years. Detailed clinical history and results of local and general examination was noted in each case. Out of 192 cases, cyto-histopathological correlation was observed only in 62 cases.

Inclusion criteria: Salivary gland FNAC performed from October 2014 to September 2017.

Exclusion criteria: Mesenchymal, hematological, or metastatic lesions.

FNAC was performed using $10 \mathrm{~mL}$ disposable syringes and 23-G needles after taking informed consent from each patient. The gross appearance of aspirate was noted and aspirate was smeared on clean glass slides. FNA dried smears were stained with May-
Grunwald-Giemsa staining technique and wet smears fixed in 95\% ethanol were stained with haematoxylin and eosin (H\&E) stain and Papanicolaou stain. All the biopsy specimens were fixed in $10 \%$ formalin and submitted for histopathological examination. H\&E stain was done in all cases.

The slides were reviewed by two pathologists in a blinded fashion. Salivary gland lesions were first studied under three groups: non-neoplastic lesions, benign and malignant tumors. Cytohistopathological correlation was performed in all available cases. The histopathological diagnosis was considered as the gold standard to assess sensitivity, specificity, and diagnostic accuracy.

Further, for risk stratification (based on MSRSGC), cytological smears of 62 cases were revaluated and salivary gland lesions were classified under six groups (non-diagnostic, non-neoplastic, atypia of undetermined significance, neoplastic-benign or uncertain malignant potential (NUMP), suspicious to malignancy and malignant). On the basis of available histopathological diagnosis, the risk of malignancy was calculated for each of the groups.

\section{Statistical analysis}

Sensitivity, specificity, positive predictive value (PPV), negative predictive value (NPV), and diagnostic accuracy was analysed with SPSS version 11.0. Risk of malignancy for each cytological category based on Milan system was calculated as the number of low-grade and high-grade malignant neoplasms divided by the total number of the cases in a given category. Likewise, the risk of high-grade malignancy was calculated as the number of high-grade malignancies diagnosed on the final histolopathologic examination divided by the total number of cases in a given category (5).

\section{Results}

The current study analyzed 192 cases of salivary gland lesions in a period of three years from October 2014 to September 2017. The clinicopathological features on FNAC are shown in Table 1. The age range for all salivary gland lesions was 6 to 85 
years and the mean age was 45.5 years. Overall male to female ratio was $0.9: 1$. Of the 192 cases, parotid gland was involved in 119 cases $(61.98 \%)$, whereas submandibular and other salivary glands were involved in 63 (32.81\%) and $10(5.21 \%)$ cases, respectively. Out of 192 patients undergoing FNAC, seven cases were non-diagnostic/unsatisfactory. There were 107 (55.73\%) non-neoplastic lesions and 78 (40.63\%) neoplastic lesions. Of the 78 neoplastic lesions, 58 (74.36\%) were benign and $20(25.64 \%)$ were malignant. Chronic sialadenitis was the most common non-neoplastic lesion (58.88\%) followed by 21 cases of cystic lesions (19.62\%). Pleomorphic adenoma (65.53\%) was the most common benign neoplasm followed by Warthin tumor (25.86\%). Mucoepidermoid carcinoma (MEC) was the most common malignant neoplasm (55\%). Adenoid cystic carcinoma (AdCC) accounted for $25 \%$ of malignant cases.

Histopathological correlation was available for 62 cases and was dissimilar to cytologic diagnosis in 13 cases (Table 2). In seven cases (two lymphoepithelial cyst, two Warthin tumor, two low-grade MEC and one salivary duct carcinoma), a cytologic diagnosis of cystic lesion was given and the final diagnosis was made based on histopathological examination. One case of acinic cell carcinoma with normal looking acinar cells was reported as sialadenosis on cytology. Two cases (one Warthin tumor and one non-Hodgkin lymphoma) were reported as chronic sialadenitis on cytology due to selective sampling of lymphoid cells. One case of pleomorphic adenoma was interpreted as basal cell adenoma due to lack of characteristic stroma. The discordant cases included two cases of AdCC and one case of polymorphous low-grade adenocarcinoma (PLGA) misdiagnosed as pleomorphic adenoma on cytology. One case of pleomorphic adenoma (PA) was misdiagnosed as AdCC on cytology due to lack of chondromyxoid stroma and presence of hyaline globules.

The false negative and false positive rates were $36.84 \%$ and $2.38 \%$, respectively. Diagnostic sensitivity and specificity of FNAC for salivary gland lesions was $63.16 \%$ and $97.62 \%$, respectively. The PPV was
$92.31 \%$ and NPV was $85.42 \%$. The diagnostic accuracy to differentiate between benign and malignant lesions was $86.88 \%$.

The cases with follow-up histopathology were further sorted into the diagnostic categories as proposed by MSRSGC and the risk of malignancy was calculated (Table 3).

There were three cases (two Warthin tumors and one low-grade MEC) in nondiagnostic category. These cases had cystic contents and benign elements only. The risk of malignancy was $33.33 \%$ for this category. The non-neoplastic category included 15 cases with lack of any evidence of neoplastic activity. However, by histopathology one case was diagnosed as NHL and the others as salivary duct carcinoma. To calculate the risk of malignancy, lymphoma case was excluded. The risk of malignancy and high-grade malignancy was $7.14 \%$ for this category. In the atypical category cases diagnosis of neoplasm could not be excluded. It was a case of retention cyst diagnosed by histopathology as low-grade MEC. The risk of malignancy was $100 \%$ for this category.

Twenty-eight cases were in the benign category. This category included definite benign cases such as PA, lipoma, Warthin tumor, etc. However, two cases from this category were diagnosed as malignant on the follow-up histopathological examination. They were one case of AdCC and one case of acinic cell carcinoma reported as PA and oncocytoma, respectively, by cytology. The risk of malignancy and highgrade malignancy was $7.14 \%$ for this category. There was one case categorized as NUMP in which diagnosis of neoplasm was certain; however, malignancy could not be ruled out. The cytological diagnosis was cellular PA with a differential diagnosis of low-grade malignancy, which on histopathology turned out to be polymorphous low-grade adenocarcinoma (PLGA). The risk of malignancy was $100 \%$ for this category.

The cases in suspicious category included smears highly suggestive of a malignant lesion, but with suboptimal cellular morphology. The cases included in this group were reported as AdCC with artifactual changes. The histopathological examination diag- 


\section{Risk-based Stratification of ...}

nosed it as AdCC. The risk of malignancy and highgrade malignancy was $100 \%$ for this category. There were 13 cases categorized as malignant neoplasm and one of these cases turned out to be PA in the followup histopathology. There was one case of PLGA, one salivary duct carcinoma, three AdCC, one acinic cell carcinoma, two low-grade MEC and four high-grade MEC. The risks of malignancy and high-grade malignancy were $92.30 \%$ and $69.23 \%$, respectively, for this category.

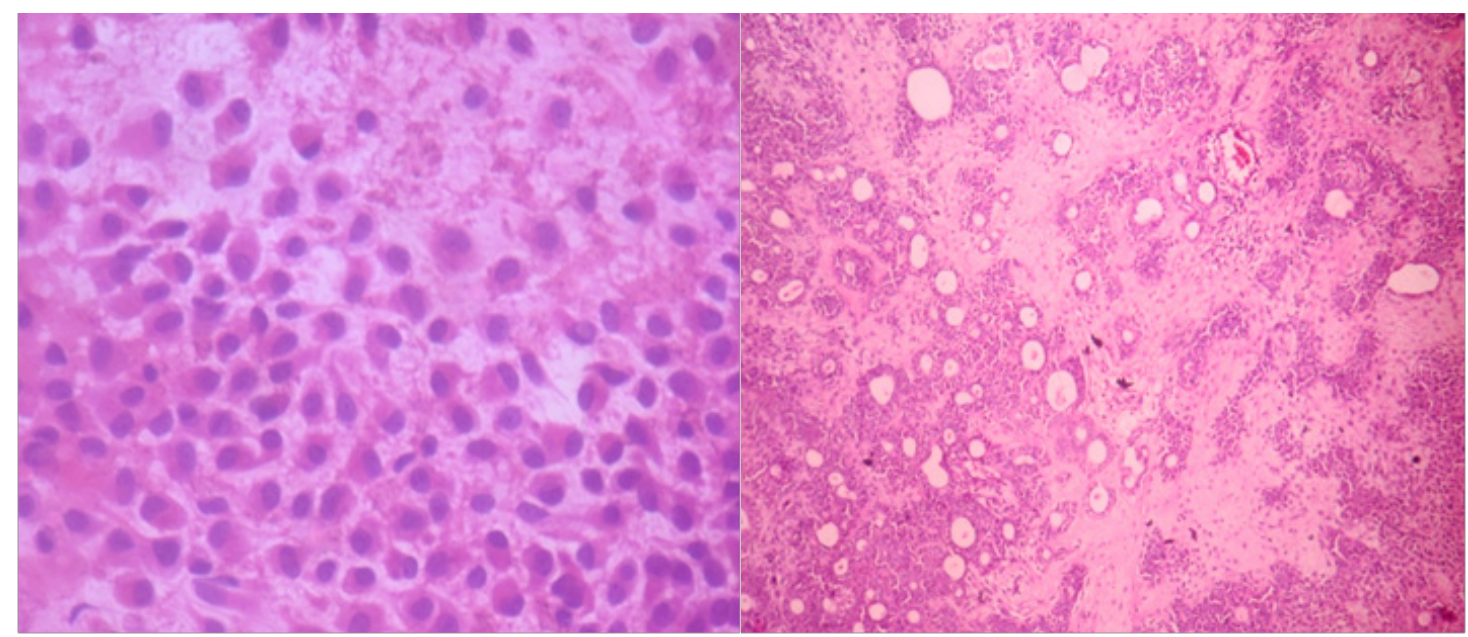

Figure 1. Pleomorphic adenoma a. Smear showing bland epithelial cells with plasmacytoid appearance and well defined cytoplasm in a myxoid background (400X, H\&E); b. Tissue section of pleomorphic adenoma (100X, H\&E)

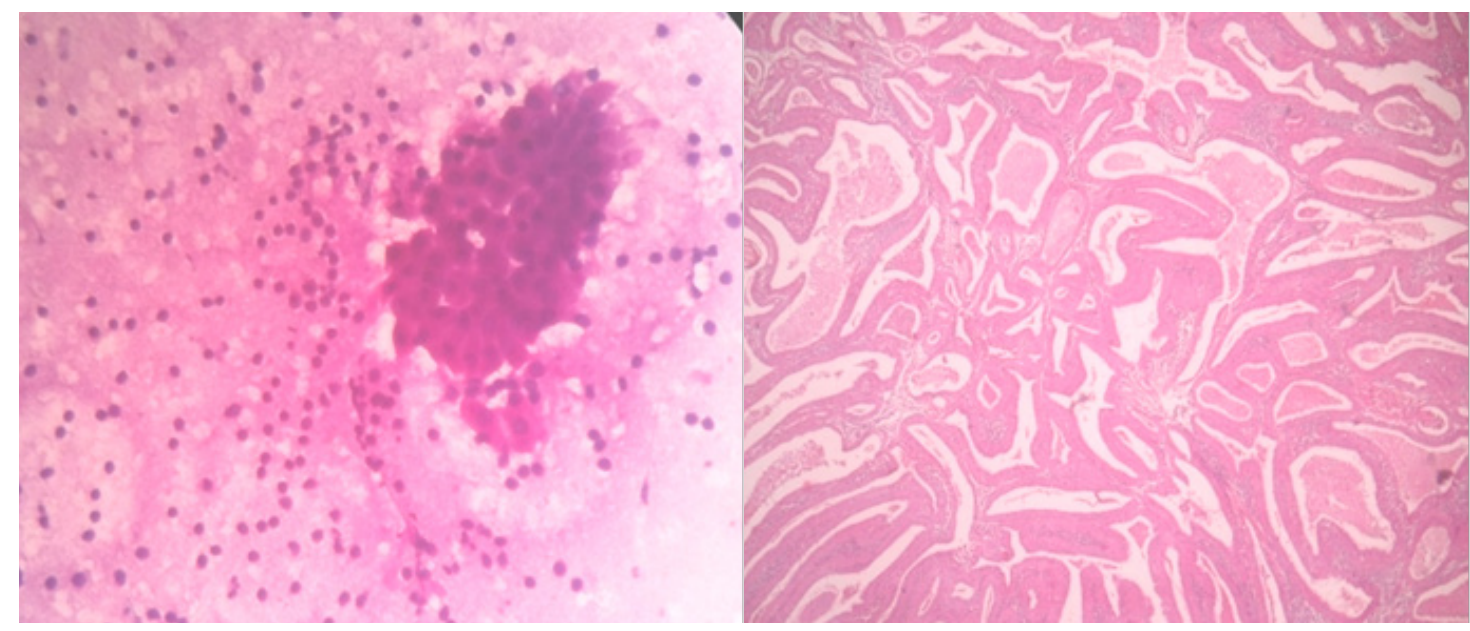

Figure 2. Warthin tumor a. Smear shows cohesive sheet of bland oncocytic cells in a background of lymphocytes (100X, $\mathrm{H} \& \mathrm{E})$; b. Tissue section of Warthin tumor (100X, H\&E).

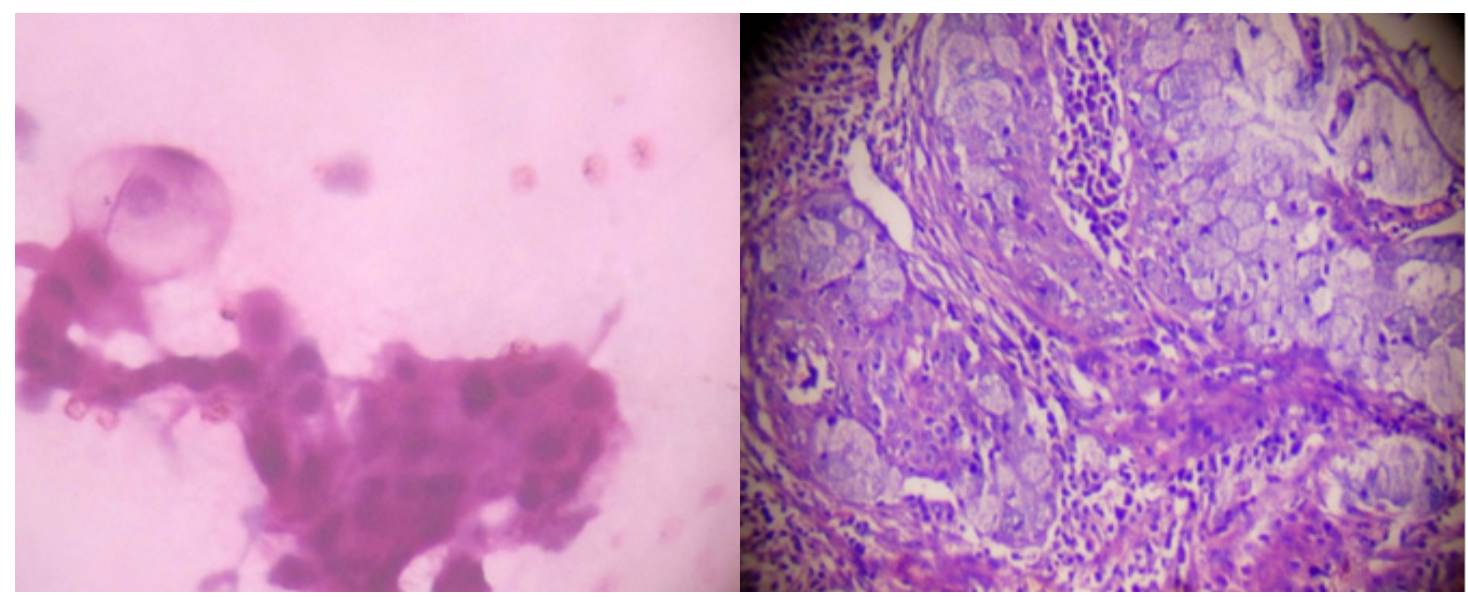

Figure 3. Mucoepidermoid carcinoma a. Smear showing cohesive cluster of atypical squamous cells and intermediate cell with cytoplasmic vacuolation (400X, H\&E); b. Tissue section of mucoepidermoid carcinoma (100X, H\&E) 

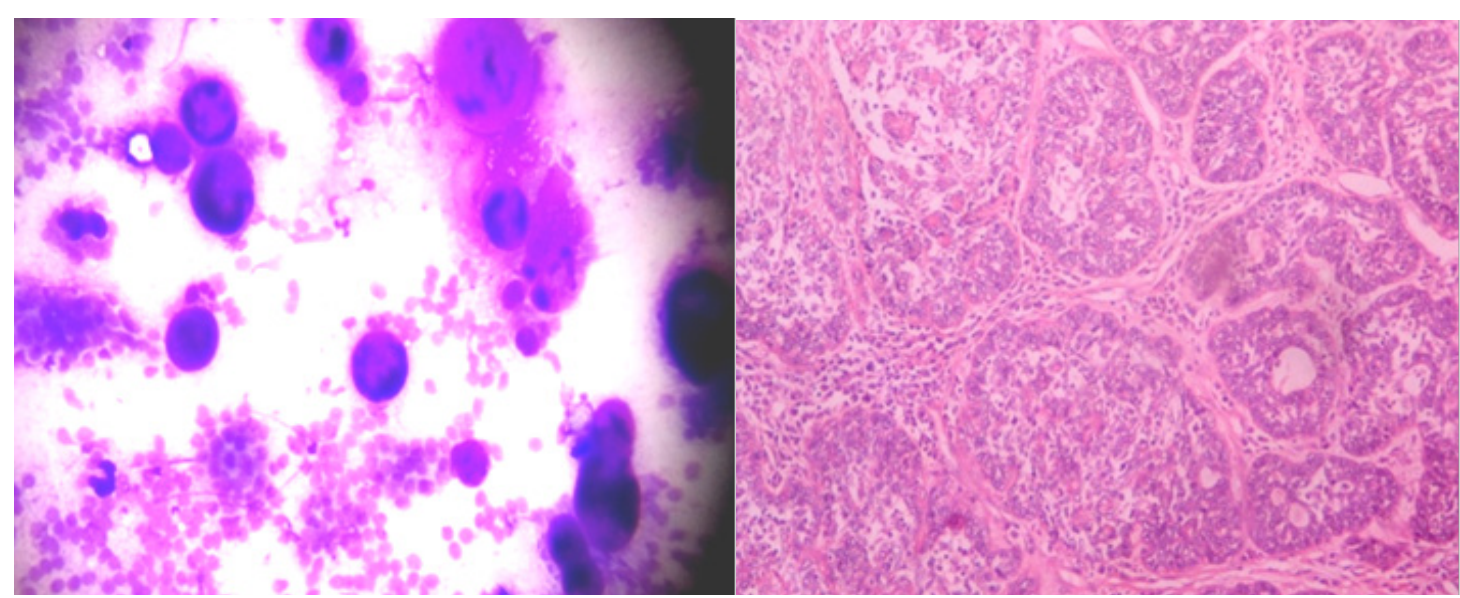

Figure 4. Adenoidcystic carcinoma a. Smear showing small uniform epithelial cells and hyaline stromal globules surrounded by cells (400X, MGG) b. Tissue section of adenoidcystic carcinoma (H\&E, 100X)

Table 1. Clinopathological Features of Salivary Glands Lesions

\begin{tabular}{|c|c|c|}
\hline Characteristics & Total No. & Percentage \\
\hline No. of Cases & 192 & \\
\hline \multicolumn{3}{|l|}{ Gender } \\
\hline Male & 91 & 47.40 \\
\hline Female & 101 & 52.60 \\
\hline \multicolumn{3}{|l|}{ Site } \\
\hline Parotid gland & 119 & 61.98 \\
\hline Submandibular gland & 63 & 32.81 \\
\hline Other & 10 & 5.21 \\
\hline Mean age, yr & $45.5(6-85)$ & \\
\hline \multicolumn{3}{|l|}{ Cytological diagnosis } \\
\hline 1.Nondiagnostic/unsatisfactory & 7 & 3.64 \\
\hline 2.Nonneoplastic & 107 & 55.73 \\
\hline Cystic lesions & 21 & 19.62 \\
\hline Sialadenosis & 6 & 5.61 \\
\hline Chronic sialadenitis & 63 & 58.88 \\
\hline Abscess & 10 & 9.35 \\
\hline Chronic granulomatous inflammation & 7 & 6.54 \\
\hline 3.Neoplastic & 78 & 40.63 \\
\hline a) Benign & 58 & 74.36 \\
\hline Pleomorphic adenoma & 38 & 65.53 \\
\hline Warthin tumor & 15 & 25.86 \\
\hline Basal cell adenoma & 3 & 5.17 \\
\hline Oncocytoma & 1 & 1.72 \\
\hline Myoepithelioma & 1 & 1.72 \\
\hline b) Malignant & 20 & 25.64 \\
\hline Mucoepidermoid carcinoma & 11 & 55 \\
\hline
\end{tabular}


225. Risk-based Stratification of ...

\begin{tabular}{|c|c|c|}
\hline Acinic cell carcinoma & 1 & 5 \\
\hline Carcinoma ex pleomorphic adenoma & 1 & 5 \\
\hline Adenoid cystic carcinoma & 5 & 25 \\
\hline Salivary duct carcinoma & 1 & 5 \\
\hline Polymorphous low-grade adenocarcinoma & 1 & 5 \\
\hline
\end{tabular}

Table 2. Cytohistological Correlation in the Study Cases

\section{Cytological Diagnosis ( $\mathrm{N}=192)$}

\section{No of Cases on Histology ( $\mathrm{N}=62)$}

\section{A. Non-neoplastic}

- $\quad$ Cystic lesions (21)

- $\quad$ Sialadenosis (6)

- Chronic sialadenitis (63)

- Abscess (10)

B. Neoplastic

- a) Benign

- PA(38)

- Warthin ( 15)

- Basal cell adenoma (3)

- Oncocytoma (1)

- b) Malignant

- $\quad$ MEC (11)

- Acinic cell carcinoma (1)

- $\operatorname{AdCC}(5)$

- Salivary duct carcinoma (1)

- $\quad$ PLGA (1)
Mucocele (1), lymphoepithelial cyst (2), Warthin tumor (2), low-grade MEC (2), salivary duct carcinoma (1)

Sialadenosis (1), acinic cell carcinoma (1)

Chronic Sialadenitis (6), NHL (1), WT (1)

Abscess (2)

PA (15), basal cell adenoma (1), AdCC (2), PLGA (1) WT (7)

PA (1), basal cell adenoma (1)

Oncocytoma (1)

MEC (6)

Acinic cell carcinoma (1)

AdCC (3), PA (1)

Salivary duct carcinoma (1)

PLGA (1)

WT $=$ Warthin tumor, $\mathrm{PA}=$ Pleomorphic adenoma, $\mathrm{AdCC}=$ Adenoid cystic carcinoma,

PLGA=Polymorphous low-grade adenocarcinoma, NHL=Non-Hodgkin lymphoma, MEC $=$ Mucoepidermoid carcinoma

Table 3. Diagnosis Based on the Proposed Milan System and Risk-based Categorization

\begin{tabular}{|c|c|c|c|c|c|c|c|}
\hline Variable & ND & $\begin{array}{c}\text { Non-neo- } \\
\text { plastic }\end{array}$ & Atypical & Benign & NUMP & $\begin{array}{l}\text { Suspicious for } \\
\text { Malignancy }\end{array}$ & Malignant \\
\hline $\begin{array}{l}\text { Total no of cases in each } \\
\text { category }\end{array}$ & 3 & 15 & 1 & 28 & 01 & 01 & 13 \\
\hline \multicolumn{8}{|l|}{$\begin{array}{l}\text { Histopathological Fol- } \\
\text { low-up }\end{array}$} \\
\hline Benign & $2(\mathrm{WT})$ & 13 & & 26 & 0 & 0 & $1(\mathrm{PA})$ \\
\hline \multirow[t]{6}{*}{ Malignant } & $\stackrel{1}{1}$ & 2 & 1 (MEC) & 2 & 1 (PLGA) & 1 (AdCC) & 12 \\
\hline & & $1 \mathrm{NHL}$ & & $(1 \mathrm{AdCC})$ & & & 1 PLGA \\
\hline & & $\begin{array}{l}1 \text { salivary duct } \\
\text { carcinoma }\end{array}$ & & $(1 \mathrm{ACC})$ & & & $1 \mathrm{SDC}$ \\
\hline & & & & & & & $\begin{array}{l}3 \mathrm{AdCC} \\
1 \mathrm{ACC}\end{array}$ \\
\hline & & & & & & & 2MEC (low-grade) \\
\hline & & & & & & & 4 MEC (high-grade) \\
\hline Risk of malignancy & $33.33 \%$ & $7.14 \%$ & $100 \%$ & $7.14 \%$ & $100 \%$ & $100 \%$ & $92.30 \%$ \\
\hline $\begin{array}{l}\text { Risk of high-grade ma- } \\
\text { lignancy }\end{array}$ & $0 \%$ & $7.14 \%$ & $0 \%$ & $7.14 \%$ & $0 \%$ & $100 \%$ & $69.23 \%$ \\
\hline
\end{tabular}

$\mathrm{WT}=$ Warthin tumor, $\mathrm{PA}=$ Pleomorphic adenoma, $\mathrm{AdCC}=$ Adenoid cystic carcinoma, $\mathrm{PLGA}=$ Polymorphous low-grade adenocarcinoma, $\mathrm{NHL}=$ Non-Hodgkin lymphoma, $\mathrm{MEC}=$ Mucoepidermoid carcinoma 


\section{Discussion}

The role of FNAC to diagnose salivary gland lesions is well established as a safe, cost-efficient, minimally invasive procedure and an aid to the clinicians in the planning of management $(2,8)$. However, at many times it becomes a challenging job to diagnose precisely, mainly due to the resemblance to normal salivary gland elements, heterogeneous nature of salivary gland lesions, overlapping features between benign and malignant lesions, presence of cystic components, and oncocytic metaplasia (9).

In the current study on 192 FNAC specimens with salivary gland lesions, $74.36 \%$ were benign and $25.64 \%$ malignant. It was similar to previous reports $(10,11,12)$. According to the literature, the rate of false negative salivary gland FNAC results can range from $0 \%-37 \%$ (13). In the current study, false negative rate on cytology was $36.84 \%$.

In the current study, there were seven false negative cases. There were two cases of low-grade MEC and one case of salivary duct carcinoma reported as cystic lesion on cytology. Review of cytology of these two cases of low-grade MEC revealed paucicellular smears showing scattered macrophages on a mucoid background. The main cause of false negative interpretation of MEC is that many of these tumors are predominantly cystic; there is dilution of smear by mucoid fluid, resemblance of mucus secreting foamy cells to histiocytes and bland looking intermediate cells $(14,15)$. The smears in case of salivary duct carcinoma revealed necrotic material only. Therefore, in case of cystic lesions, reaspiration of any residual mass may be helpful to reduce sampling errors (11). One case of acinic cell carcinoma was reported as sialadenosis on cytology. In this false negative case, smears showed normal looking acinar cells. The distinction between sialadenosis and acinic cell carcinoma may be difficult. However, unlike sialadenosis, normal tissues including adipose and ductal cells are not represented in smears of acinic cell carcinoma and cluster of cells are larger and more irregular. Two cases reported as PA on cytology were diagnosed as AdCC in histopathology. The smears showed focal fibro- myxoid stroma and occasional hyaline stromal globules. Exact diagnosis of poorly differentiated AdCC may be difficult due to the absence of characteristic stromal matrix (16). This differentiation is important since the surgical management is different. One case of PLGA in cytopathology was reported as PA in cytology. In the current study, review of the cytological smear showed metachromatic stroma and bland looking cells. The cells of PA usually show plasmacytoid myoepithelial cells and do not form pseudopapillary or tubular structures typical of PLGA (17). Thus, the various causes for false negative results can be summed up as nonrepresentative samples, observational errors, presence of cystic material, complexity of cytological patterns with overlapping morphological features and bland cytological features leading to underassessment of low-grade malignant tumors.

The false positive rate is reported to be low and the rate ranges $0 \%$ to $10 \%$ in the literature (8). In the current study, false positive rate was $2.38 \%$ since it histopathologically confirmed one case of PA misdiagnosed as AdCC on cytology. The smears showed the presence of hyaline globules with occasional blending of epithelial cells. The false positive diagnoses could be due to lack of representative sample.

In the current study, diagnostic sensitivity and specificity of FNAC for salivary gland lesions were $63.16 \%$ and $97.62 \%$, respectively, which was in agreement with the existing literature (12). The diagnostic accuracy to differentiate between benign and malignant lesions was $86.88 \%$, which correlated with that of Tessy PJ et al. (18).

Therefore, considering the limitations such as low sensitivity and high false negative rate, it is important to report salivary gland FNAC on the basis of a riskbased diagnostic classification scheme to standardize interpretation of results and effective clinical management of patients. The current analysis risk-based stratification was performed on 61 lesions with histologic follow-up using the recommended MSRSGC (one case of lymphoma excluded as per exclusion criteria). The aim of Milan system is to provide a uniform classification system that assists in communica- 
tion between the cytopathologists and surgeons, cytological, and histopathological correlation of cases, clinical decision making, and interobserver comparison of results (7). In the current study, the number of cases in each diagnostic category and the risk of malignancy (ROM) were as follows: nondiagnostic three cases (ROM; 33.33\%), nonneoplastic - 14 cases (ROM; 7.14\%), atypical - one case (ROM; 100\%), benign -28 cases (ROM - 7.14\%), NUMP - one case (ROM; 100\%), suspicious one case (ROM; 100\%), and malignant - 13 cases (ROM; 92.30\%). In a similar study on 631 salivary gland aspirates by Rohilla $M$ et al., the overall risk of malignancy for the unsatisfactory, nonneoplastic, atypical, benign neoplasm, NUMP, and positive for malignancy categories were $0 \%, 17.4 \%, 100 \%, 7.3 \%, 50 \%$, and $96 \%$, respectively (20). In another study by Wei S et al., based on the review of 29 studies comprising 4514 cases of salivary gland FNAC, the cumulative risk of malignancy of each diagnostic category was: nondiagnostic $-25 \%$, nonneoplastic $-10.2 \%$, benign $-3.4 \%$, NUMP $-37.5 \%$ suspicious for malignancy $-58.6 \%$ and malignant $-91.9 \%$ (6) . Results of the current study were comparable to those of these studies.

The current study also calculated the risk of highgrade malignancy, which ranged from $7.14 \%$ for benign neoplasms to $69.23 \%$ for malignant neoplasms. This correlated with the existing literature $(12,19)$.

\section{Conclusion}

In conclusion, the current study highlighted the utility of FNAC as a safe and effective modality in diagnosis and planning management of patients with salivary gland lesions despite its inherent limitations. A risk based stratification scheme as recommended by MSRSGC provides a standard method to analyse the results in cases showing overlapping morphological features and may be of utmost value in enhancing the diagnostic accuracy of salivary gland FNAC with promising impact on clinical management.

\section{Conflict of Interests}

Authors declared no conflict of interests.

\section{References}

1. Barnes L, Eveson JW, ReichertP, Sidransky D. Pathology and genetics of head and neck tumors. In P.Kleihues and L. H. Sobin, editors. World Health Organization Classification of Tumors. Lyon, France: IARC Press; 2005.

2. Wong DS, Li GK. The role of fine needle aspiration cytology in the management of parotid tumors: a critical clinical appraisal. Head Neck. 2000;22(5):469-73. PMID:10897106

3. Cibas ES, Ducatman BS. Cytology:Diagnostic Principles and Clinical Correlates. 3nd ed. Philadelphia: Elsevier Health Sciences; 2008. PMCID:PMC2365970

4. StewartCJ, MacKenzie K, McGarry GW, Mowat A. Fine-needle aspiration cytology of the salivary gland: a review of 341 cases. Diagn Cytopathol. 2000;22(3):139-46. https://doi.org/10.1002/ (SICI) 1097-0339(20000301)22:3<139::AIDDC2>3.0.CO;2-A PMID: $\underline{10679992}$

5. Griffith CC, Pai RK, Schneider F, Duvvuri U, Ferris RL, Johnsan JT et al. Salivary gland tumor fine-needle aspiration cytology: A proposal for a risk stratification classification. Am J Clin Pathol. 2015;143(6):839-53. https://doi.org/10.1309/AJCPMII6OSD2HSJA PMID:25972326 PMCID:PMC5257286

6. Wei S, Layfield LJ, LiVolsi VA, Montone KT, Baloch ZW. Reporting of fine needle aspiration (FNA) specimens of salivary gland lesions: A comprehensive review. Diagn Cytopathol. 2017;45(9):820-7. https://doi.org/10.1002/ dc.23716 PMID:28371507

7. Baloch ZW, Faquin WC, Layfield LJ. Is it time to develop a tiered classification scheme for salivary gland fine-needle aspiration specimens? Diagn Cytopathol. 2017;45(4):285-6. https://doi. org/10.1002/dc.23601 PMID:27629108

8. Mairembam P, Jay A, Beale T, Morley S, Vaz F, Kalavrezos N, et al. Salivary gland FNA cytology : role as a triage tool and an approach to pitfalls in cytomorphology. Cytopathology. 2016;27(2):91-6. https://doi.org/10.1111/ cyt.12232 PMID:25656853

9. Tyagi R, Dey P. Diagnostic problems of salivary gland tumors. Diagn Cytopathol. 2015;43(6):495-509. https://doi.org/10.1002/ 


\section{$\underline{\text { dc.23255 PMID:25614439 }}$}

10. Milashi H, Kawahara A, Kage M, Kojiro M, Nakashima T, Umeno H, et al. Comparision of preoperative fine-needle aspiration cytology diagnosis and histopathological diagnosis of salivary gland tumors. Kurume Med J. 2006;53(12):23-7. PMID:17043392

11. Rajwanshi A, Gupta K, Gupta N, Shukla R, Srinivasan R, Nijhawan R, et al. Fine-needle aspiration cytology of salivary glands: Diagnostic pitfalls - Revisited. Diagn Cytopatol. 2006;34:580-4. https://doi.org/10.1002/dc.20353 PMID: $\underline{16850487}$

12. Rossi ED, Wong LQ, Bizzarro T, Petrone G, Mule A, Fadda G, et al. The impact of FNAC in the management of salivary gland lesions: Institutional experiences leading to a risk-based classification scheme. Cancer Cytopathol. 2016;124(6):388-96. https://doi.org/10.1002/ cncy.21710 PMID:26959289

13. Ashraf A, Saikh AS, Kamal F, Sarfaraz R, Bukhari MH. Diagnostic reliability of FNAC for salivary gland swellings: A comparative study. Diagn Cytopathol. 2010;38(7):499-504. https://doi.org/10.1002/dc.21211 PMID:19950398

14. Heller KS, Dubner S, Chess Q, Attie JN. Value of fine needle aspiration biopsy of salivary gland masses in clinical decision-making. Am J Surg. 1992;164(6):667-70. https://doi.org/10.1016/

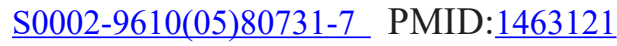

15. Al-Khafaji M, Nestok R, Katz L. Fine- needle aspiration of 154 cases parotid masses with histopathologic correlation: ten-year experience at the University of Texas M.D. Anderson Cancer Center. Cancer. 1998;84(3):153-9. https://doi.org/10.1002/ (SICI) 1097-0142(19980625)84:3<153::AID-CNCR6>3.0.CO;2-P PMID: $\underline{9678729}$

16. Vaidhya S, Sinha A, Narayan S, Adhikari S, Sabira KC. A comparative study of fine-needle aspiration cytology and histopathology in salivary gland lesions. Journal of Pathology of Nepal. 2011;1(2):108-13. https://doi.org/10.3126/ jpn.v1i2.5403

17. Klijanienko J, Viehl P. Salivary Gland Tumors: Monographs in clinical cytology. Vol 15. Basel, Switzerland: Karger; 2000. https://doi. org/10.1159/isbn.978-3-318-00544-8

18. Tessy PJ, Jayalekshmy PS, Cicy PJ, Poothiode U. Fine needle aspiration cytology of salivary gland lesions with histopathological correlation - A two year study. International J of Healthcare and Biomedical Research. 2015;3(4):919. https://pdfs.semanticscholar.org/55dc/ a5991718d17bd584939e7b8c1b1cfc813c66. pdf

19. Rohilla M, Singh P, Rajwanshi A, Gupta N, Srinivasan R, Dey P, et al. Three-year cytohistological correlation of salivary gland FNA cytology at a tertiary centre with the application of the Milan system for risk stratification. Cancer Cytopathol. 2017;125(10):767-75. https://doi. org/10.1002/cncy.21900 